\title{
Analisis Pengendalian Bahan Baku Pada UMKM Kampoeng Cookies and Rotte Di Pekanbaru Riau
}

\author{
NURHAYANI LUBIS \\ Dosen Tetap Fakultas Ekonomi Universitas Lancang Kuning \\ Jalan Yos Sudarso KM 8 Rumbai Telp. (0761) 52581 \\ Email: nurhayanilubis@unilak.ac.id
}

\begin{abstract}
This study to calculate the most economical inventory levels on three main raw materials of wheat flour, sugar, and butter in small and medium micro enterprises in Kampoeng Cookies and Rotte. The result of this research is that EOQ on wheat flour raw material is $289 \mathrm{~kg}$ with purchase 5 times a year. On raw material of sugar, EOQ yield is 141 $\mathrm{kg}$ with purchase 5 times a year. Then on butter raw material, EOQ result is $112 \mathrm{~kg}$ with purchase 5 times a year.
\end{abstract}

Keywords: Micro, small and medium enterprises SMEs, EOQ

Pekanbaru merupakan salah satu daerah yang memiliki pertumbuhan UMKN yang tinggi. Jumlah UMKM di Pekanbaru menjadi jumlah terbanyak dibandingkan dengan jumlah UMKM di kabupaten atau kota lainnya di Riau. Data Dinas Koperasi dan UKM Riau menyebutkan bahwa Pekanbaru dengan 68.728 UMKM-nya menempati posisi pertama dalam jumlah UMKM. Seperti perusahaan lainnya, tujuan didirikannya UMKM adalah memeproleh laba. Tentu saja laba di peroleh dangan kelancaran proses produksi. Proses produksi yang lancar merupakan salah satu yang menjaga kelangsungan suatu usaha ataupun perusahaan.

Kelangsungan proses produksi dapat dijaga dengan menjaga kelangsungan bahan baku. Bahan baku yang dikelola secara baik dan efisien dapat mengurangi biaya-biaya yang keluar akibat kesalahan dalam pemesanan, penyimpanan bahan baku. Kesalahan dalam mengelola bahan baku juga menyebabkan pengeluaran biaya untuk upah pekerja. Akan tetapi hendaknya kuantitas persediaan itu jangan terlalu besar agar modal yang tertanam dalam persediaan dan biaya-biaya yang ditimbulkannya dengan adanya persediaan juga tidak terlalu besar dan jangan pula terlalu kecil karena dapat memperlambat proses produksi.
Kegagalan pengendalian persediaan bahan baku akan menyebabkan kegagalan dalam memperoleh laba. Kekurangan bahan baku dapat menghambat produksi atau merubah jadwal produksi, sedangkan kelebihan persediaan bahan baku menyebabkan peningkatan biaya dan penurunan laba. Apabila perusahaan tidak menggunakan metode yang tepat dalam mengendalikan persediaan bahan bakunya, maka akan berdampak negatif pada perolehan laba yang seharusnya dapat dicapai perusahaan secara optimal disetiap tahunnya (Hidayah, 2016).

Kampoeng Cookies and Rotte merupakan salah satu UMKM yang bergerak di bidang makanan berupa roti dan kue-kue kering. Kampoeng Cookies and Rotte memiliki 2 gerai yaitu Kampoeng Cookies dan Rotte. Berdiri sejak 10 tahun yang lalu dan sekarang Kampoeng Cookies dapat di kategorikan sebagai usaha menengah yang memiliki omset yang cukup besar untuk ukuran UMKM. Memiliki omset sekitar 10 Milyar rupiah beberapa tahun terakhir dan diharapkan dapat meningkat terus untuk tahun-tahun berikutnya. Kampoeng Cookies And Rotte menghabiskan bahan baku untuk proses produksinya yaitu: Tepung Terigu sebanyak 1,5 ton perbulan, 
gula sebanyak $500 \mathrm{~kg}$ setiap bulan dan untuk mentega menghabiskan $750 \mathrm{~kg}$ per bulannya.

Didukung oleh data yang ada dan penelitian-penelitian terdahulu, kami melihat bahwa hal ini sangat penting dan kami ingin meneliti tentang pengendalian bahan baku yang terdapat di Kampoeng Cookies and Rotte tersebut, dan kami mengangkat judul penelitian ini adalah Pengendalian Persediaan Bahan Baku Dengan Economic Order Quantity (EOQ) Pada Kampoeng Cookies and Rotte.

Berdasarkan latar belakang masalah tersebut, maka penulis menarik perumusan masalah sebagai berikut, yaitu berapa besar penggunaan tepung terigu, gula pasir, dan mentega yang optimal dengan menggunakan metode Economic Order Quantity (EOQ) pada Kampoeng Cookies and Rotte?

Beberapa penelitian yang menunjang untuk dilakukan penelitian ini antara lain penelitian yang dilakukan oleh Hidayah tahun 2016 yang melakukan penelitian tentang "Analisis Pengendalian Persediaan Bahan Baku Tepung Terigu Citarasa Bakery pada PT Kaltim Multi Boga Utama (KMBU) di Bontang”. Penelitian oleh Prihartono, dkk tahun 2014 melakukan penelitian tentang pengendalian bahan baku pada perusahaan tahu. Oleh Fajrin tahun 2015 melakukan penelitian tentang pengendalian bahan baku dengan metode Economic Orde Quantity (EOQ) pada perusahaan roti bonansa di Semarang. Penelitian yang dilakukan oleh Ruauw tahun 2011 yang meneliti tentang pengendalian persediaan bahan baku pada usaha Grenda Bakery Lianli, Manado.

Pengertian tentang EOQ menurut beberapa ahli dapat dilihat sebagai berikut, Heizer dan Render (2010) menerangkan bahwa EOQ merupakan sebuah teknik kontrol persediaan yang meminimalkan biaya total dari pemesanan dan penyimpanan. Metode EOQ atau pembelian bahan baku dan suku cadang yang optimal sesuai yang diutarakan Slamet (2007) dapat diartikan diartikan sebagai kuantitas bahan baku dan suku cadangnya yang dapat diperoleh melalui pembelian jumlah pembelian dengan mengeluarkan biaya minimal tetapi tidak berakibat pada kekurangan dan kelebihan bahan baku dan suku cadangnya. Menurut Riyanto (2011) Economic Order Quantity (EOQ) adalah jumlah kuantitas barang yang dapat diperoleh dengan biaya yang minimal atau sering dikatakan sebagai jumlah pembelian yang optimal. Sedangkan menurut Assauri (2008) Economic Order Quantity (EOQ) merupakan jumlah atau besarnya pesanan yang dimiliki jumlah ordering cost dan carrying costper tahun yang paling minimal.

\section{METODE}

Penelitian ini dilakukan pada di UMKM Kampoeng Cookies and Rotte tepatnya dijalan Bukit Barisan Kota Pekanbaru. Data yang digunakan untuk menganalisis pemesanan atau pembelian paling ekonimis (Economic Order Quantity) EOQ pada persediaan bahan baku adalah data sekunder yang diperoleh dari UMKM Kampoeng Cookies and Rotte. Selain itu, digunakan pula data hasil penelitian yang ada, terutama hasil temuan dari para ahli dibidang pengendalian persediaan bahan baku. Tenik analisis data menggunanakan analisis data kuantitatif dengan menggunakan formula EOQ sebagai berikut: formula :

Atau EOQ dapat juga dicari dengan $\mathrm{Q}=\sqrt{\frac{2 \times \mathrm{R} \times \mathrm{O}}{\mathrm{P} \mathrm{I}}}$ dan dapat juga dihitung dengan rumus :

TAC = Total Annual Inventory Cost (Total Biaya Persediaan Tahunan)

Dengan Rumus :

Keterangan :

$$
\mathrm{TAC}=(\mathrm{Q} / 2) \mathrm{C}+(\mathrm{R} / \mathrm{Q}) \mathrm{S}+\mathrm{R}
$$

$\mathrm{Q}=$ Kuantitas pemesanan (unit/order)

$\mathrm{R}=$ Jumlah pembelian (permintaan) selama satu periode 
$\mathrm{C}=$ Biaya simpan tahunan dalam Rupiah (unit)

$\mathrm{P}=$ Harga $/ \mathrm{Kg}$

$\mathrm{S}=$ Biaya setiap kali pesan

\section{HASIL}

\section{Jumlah Pembelian Bahan Baku Tepung Terigu Selama 1 Tahun}

Selama kurun waktu tahun 2015 jumlah pembelian bahan baku Tepung Terigu yang dibeli oleh kampoeng cookies and rotte sejumlah $1.500 \mathrm{Kg}$, biaya yang dikeluarkan setiap kali melakukan pemesanan tepung terigu adalah $\mathrm{Rp}$ 25.000. Harga tepung terigu ini selalu mengalami kenaikan dan penurunan, tetapi harga yang tidak stabil tersebut tidak mengganggu produksi di Kampoeng Cookies and Rotte, kenaikan tersebut berkisar antara Rp8.000 sampai dengan Rp9.000 per kilogramnya, dana apabila terjadi penurunan harga tepung terigu akan memberikan tambahan bagi kampoeng cookies and rotte. Biaya yang dikeluarkan selama pesediaan ada di gudang adalah sebesar $10 \%$ dari nilai rata-rata persediaan yang digunakan, yakni dengan persediaan sebesar $1.500 \mathrm{Kg}$ dikalikan 10\%. Untuk penghitungan kebutuhan selama tahun 2015 dapat digunakan metode EOQ yang terlihat seperti berikut:

Perhitungan dengan formula EOQ untuk tepung terigu:

$$
\begin{aligned}
& \mathrm{EOQ}=\sqrt{\frac{2 \times \mathrm{R} \times \mathrm{O}}{\mathrm{P} \times \mathrm{I}}} \\
& \mathrm{EOQ}=\sqrt{\frac{2 \times 1.500 \times 25.000}{9.000 \times 10 \%}} \\
& \mathrm{EOQ}=\sqrt{\frac{75.000 .000}{900}}
\end{aligned}
$$$$
=283,67 \text { dibulatkan menjadi } 289 \mathrm{~kg}
$$

Jadi, pembelian tepung terigu yang paling ekonomis adalah $289 \mathrm{~kg}$, dengan frekuensi pemesanan 5 kali/tahun, dengan perhitungan sebagai berikut, 1500/289 $=5$ kali/tahun. Jangka waktu antar tiap pesanan ialah jumlah hari kerja pertahun/Frekuensi Pesanan $=365 / 5=73$ hari Frekuensi pesanan. Frekuensi pemesanan dapat dilihat dalam Tabel 1 yaitu:
Tabel 1. Frekuensi Pemesanan Tepung Terigu Selama Tahun 2015

\begin{tabular}{|l|c|c|c|c|c|}
\hline \multirow{2}{*}{\multicolumn{1}{|c|}{ Uraian }} & \multicolumn{5}{|c|}{ Frekuensi Pemakaian } \\
\cline { 2 - 6 } & $\mathrm{Ke}-1$ & $\mathrm{Ke}-2$ & $\mathrm{Ke}-3$ & $\mathrm{Ke}-4$ & $\mathrm{Ke}-5$ \\
\hline Kebutuhan 1 Tahun & 1.500 & 750 & 500 & 375 & 300 \\
\hline Rata-rata Persediaan & 750 & 375 & 250 & 187,5 & 150 \\
\hline Biaya Pesan & 25.000 & 50.000 & 75.000 & 100.000 & 125.000 \\
\hline Biaya Simpan & 75 & 37,5 & 25 & 18,75 & 15 \\
\hline Kali Rp 9.000/Kg & 675.000 & 337.500 & 225.000 & 168.750 & 135.000 \\
\hline \multicolumn{1}{|c|}{ TC } & 700.000 & 387.500 & 300.000 & 268.750 & 260.000 \\
\hline
\end{tabular}

Sumber : Data Olahan EOQ

Dilihat dari Tabel 1 frekuensi pemesanan tepung terigu selama tahun 2015 dapat dideskipsikan sebagai berikut, untuk pemesanan pertama membutuhkan biaya sebesar Rp 700.000, pada pemesanan kedua membuthkan biaya sebesar Rp 387.500, pemesanan ketiga membutuhkan biaya sebesar Rp 300.000, pemesanan keempat membutuhkan biaya sebesar $\mathrm{Rp}$ 268.000, dan yang lebih efisien pada pemesanan kelima membutuhkan biaya sebesar Rp 260.000. Dengan kuantitas pemesanan 5 kali pesan bisa menghemat pengeluaran bagi Kampoeng Cookies and Rotte dalam pembelian bahan baku untuk membuat berbagai macam roti untuk di jual ke konsumen. Dengan demikian kampoeng cookies and rotte bisa memperkirakan biaya yang harus dikeluarkan untuk membeli tepung terigu untuk salah satu bahan baku membuat roti.

Berikut ini bisa dilihat dari total biaya persediaan tahunan (Total Annual Inventory Cost) sesuai data pesanan yang ada:

Tabel 2. Total Biaya Persediaan Tepung Terigu Selama Tahun 2015

\begin{tabular}{|l|l|}
\hline$\sum$ Pesanan & Harga perunit \\
\hline $0-1.499 \mathrm{Kg}$ & Rp. $9.000,-$ \\
\hline 1.500 lebih & Rp. $8.000,-$ \\
\hline
\end{tabular}

Sumber : Kampoeng Cookies and Rotte Dengan rumus:

$$
\mathrm{TAC}=(\mathrm{Q} / 2) \mathrm{C}+(\mathrm{R} / \mathrm{Q}) \mathrm{S}+\mathrm{R}
$$

Keterangan:

$\mathrm{Q}=$ Kuantitas pemesanan (unit/order)

$\mathrm{R}=$ Jumlah pembelian (permintaan) selama satu periode

$\mathrm{C}=$ Biaya simpan tahunan dalam Rupiah (unit)

$\mathrm{P}=\mathrm{Harga} / \mathrm{Kg}$ 
$\mathrm{S}=$ Biaya setiap kali pesan

Dalam hal ini hanya dicari 2 total biaya tahunan pada tingkat EOQ, yaitu 1.400 $\mathrm{Kg}$ dan $1.500 \mathrm{Kg}$, yakni sebagai berikut:

1. TAC pada EOQ $1400 \mathrm{Kg}$

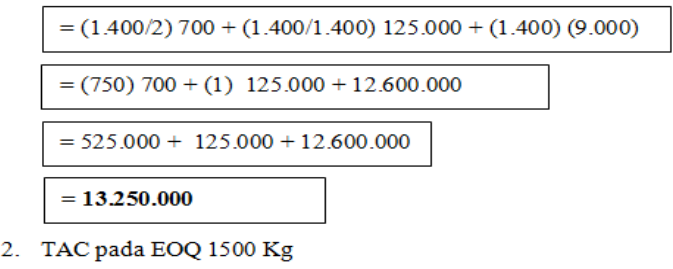

$=(1.500 / 2) 750+(1.500 / 1.500) 125.000+(1.500)(8.000)$
$=(750) 750+(1) 125.000+12.000 .000$
$=562.500+125.000+12.000 .000$
$=\mathbf{1 2 . 6 8 7 . 5 0 0}$

\section{Jumlah Pembelian Bahan Baku Gula Selama 1 Tahun}

Selama kurun waktu tahun 2015 jumlah pembelian bahan baku gula yang dibeli oleh Kampoeng Cookies and Rotte sejumlah $750 \mathrm{~kg}$, biaya yang dikeluarkan setiap kali melakukan pemesanan gula adalah Rp 20.000. Adanya kenaikan dan penurunan harga tidak begitu bermasalah buat pelaku usaha berkisar Rp 14.000 sampai dengan Rp 15.000 per kilogramnya dan biaya simpan gula adalah $10 \%$ dari nilai rata-rata persediaan. Untuk perhitungan kebutuhan selama tahun 2015 dapat digunakan metode EOQ yang terlihat seperti berikut:

Perhitungan dengan formula EOQ untuk gula:

$$
\begin{aligned}
& \text { EOQ }=\sqrt{\frac{2 \times \mathrm{R} \times 0}{\mathrm{P} \mathrm{I}}} \\
& \mathrm{EOQ}=\sqrt{\frac{2 \times 750 \times 20.000}{15.000 \times 10 \%}}
\end{aligned}
$$$$
\mathrm{EOQ}=\sqrt{\frac{30.000 .000}{1500}}=\sqrt{20.000}
$$$$
=141,421 \text { dibulatkan }(141) \mathrm{kg}
$$

Perhitungan EOQ menunjukkan pembelian gula yang paling ekonomis adalah $141 \mathrm{~kg}$, dengan frekuensi pemesanan sebanyak 5 kali/tahun yaitu 750/141 = 5 kali/tahun. Jangka waktu setiap pemesanan ialah jumlah hari kerja pertahun/frekuensi pesanan $=365 / 5=73$ hari, dengan kata lain bahawa akan dilakukan pemesanan setiap 73 hari sekali. Untuk lebih jelasnya dapat dialihat pada Tabel 3:

Tabel 3. Frekuensi Pemesanan Gula Selama Tahun 2015

\begin{tabular}{|l|c|c|c|c|c|}
\hline \multirow{2}{*}{\multicolumn{1}{|c|}{ Uraian }} & \multicolumn{5}{|c|}{ Frekuensi Pesanan } \\
\cline { 2 - 6 } & Ke-1 & Ke-2 & Ke-3 & Ke-4 & Ke-5 \\
\hline Kebutuhan 1 Tahun & 750 & 375 & 250 & 187,5 & 150 \\
\hline Rata-rata Persediaan & 375 & 187,5 & 125 & 93,75 & 75 \\
\hline Biaya Pesan & 20.000 & 40.000 & 60.000 & 80.000 & 100.000 \\
\hline Biaya Simpan & 37,5 & 18,75 & 12,5 & 9,375 & 7,5 \\
\hline Kali Rp 15.000/Kg & 562.500 & 281.250 & 187.500 & 140.625 & 112.500 \\
\hline TC & 582.500 & 321.250 & 247.500 & 220.625 & 212.500 \\
\hline
\end{tabular}

Sumber : Data Olahan EOQ

Dilihat dari Tabel 3, frekuensi pemesanan gula selama tahun 2015 bisa dijelaskan yaitu untuk pemesanan pertama akan mengeluarkan biaya sebesar Rp 582.500,-, pemesanan kedua mengeluarkan biaya sebesar $\mathrm{Rp} 321.250,-$, pemesanan ketiga mengeluarkan biaya sebesar $\mathrm{Rp}$ 247.500,-, pemesanan keempat mengeluarkan biaya sebesar Rp 220.625,dan yang lebih efisien pada saat pemesanan kelima mengeluarkan biaya sebesar $\mathrm{Rp}$ 212.500,-, dengan kuantitas pemesanan 5 kali dalam satu tahun, dapat menghemat pengeluaran bagi Kampoeng Cookies and Rotte dalam pembelian bahan baku gula untuk membuat berbagai macam roti untuk di jual. Dengan demikian Kampoeng Cookies and Rotte bisa memperkirakan biaya yang harus dikeluarkan.

Berikut ini bisa dilihat dari Total Biaya Persediaan Tahunan (Total Annual Inventory Cost sesuai data pesanan yang ada:

Tabel 4. Total Biaya Persediaan Gula Selama Tahun 2015

\begin{tabular}{|l|l|}
\hline$\sum$ Pesanan & Harga perunit \\
\hline $0-749 \mathrm{Kg}$ & Rp. $15.000,--$ \\
\hline 750 lebih & Rp. $14.000,-$ \\
\hline
\end{tabular}

Dengan rumus:

$\mathrm{TAC}=(\mathrm{Q} / 2) \mathrm{C}+(\mathrm{R} / \mathrm{Q}) \mathrm{S}+\mathrm{R}$

Keterangan:

$\mathrm{Q}=$ Kuantitas pemesanan (unit/order)

$\mathrm{R}=$ Jumlah pembelian (permintaan) selama satu periode

p.ISSN: $2407-800 X \quad$ e.ISSN: $2541-4356$ 
$\mathrm{C}=$ Biaya simpan tahunan dalam Rupiah (unit)

$\mathrm{P}=\quad$ Harga $/ \mathrm{Kg}$

$\mathrm{S}=\quad$ Biaya setiap kali pesan

Dalam hal ini hanya dicari 2 total biaya tahunan pada tingkat EOQ, yaitu 700 $\mathrm{Kg}$ dan $750 \mathrm{Kg}$, yakni sebagai berikut:

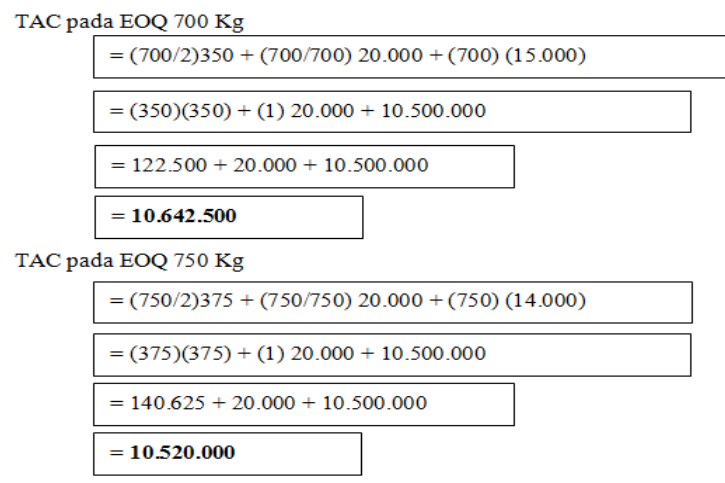

\section{Jumlah Pembelian Bahan Baku Mentega Selama 1 Tahun}

Selama kurun waktu tahun 2015 jumlah pembelian bahan baku mentega yang dibeli oleh Kampoeng Cookies and Rotte sejumlah $500 \mathrm{~kg}$, biaya yang dikeluarkan setiap kali melakukan pemesanan mentega adalah Rp 25.000, dengan harga yang naik turun dan tidak begitu bermasalah buat pelaku usaha berkisar Rp 19.000 sampai dengan 22.000 perkilogramnya dan biaya simpan $10 \%$ dari nilai rata-rata persediaan. Untuk penghitungan kebutuhan selama tahun 2015 dapat digunakan metode EOQ yang terlihat seperti berikut:

a. Perhitungan dengan formula EOQ:

$\begin{aligned} \mathrm{EOQ} & =\sqrt{\frac{2 \times \mathrm{R} \times \mathrm{O}}{\mathrm{P} \times \mathrm{I}}} \\ \mathrm{EOQ} & =\sqrt{\frac{2 \times 500 \times 25.000}{20.000 \times 10 \%}} \\ \mathrm{EOQ} & =\sqrt{\frac{25.000 .000}{2.000}} \\ \mathrm{EOQ} & =\sqrt{12.500} \\ & =111,8 \text { dibulatkan }(112) \mathrm{kg} \\ & \quad \text { Untuk pembelian mentega yang }\end{aligned}$ paling ekonomis adalah $112 \mathrm{~kg}$, dengan frekuensi pemesanan 5 kali/tahun yaitu $500 / 112=5$ kali $/$ tahun dan jangka waktu setiap kali pemesanan ialah Jumlah hari kerja pertahun/frekuensi pesanan $=365 / 5=73$ hari frekuensi pesanan. Dan dapat dilihat dalam Tabel 6 frekuensi 5 kali pemesanan yaitu:

Tabel 5. Frekuensi Pemesanan Mentega Selama Tahun 2015

\begin{tabular}{|l|c|c|c|c|c|}
\hline \multirow{2}{*}{\multicolumn{1}{c|}{ Uraian }} & \multicolumn{5}{|c|}{ Frekuensi Pesanan } \\
\cline { 2 - 6 } & Ke-1 & Ke-2 & Ke-3 & Ke-4 & Ke-5 \\
\hline Kebutuhan 1 Tahun & 500 & 250 & 166,67 & 125 & 100 \\
\hline Rata-rata Persediaan & 250 & 125 & 83,33 & 62,5 & 50 \\
\hline Biaya Pesan & 25.000 & 50.000 & 75.000 & 100.000 & 125.000 \\
\hline Biaya Simpan & 25 & 12,5 & 8,33 & 6,25 & 5 \\
\hline Kali Rp 15.000/Kg & 500.000 & 250.000 & 166.667 & 125.000 & 100.000 \\
\hline \multicolumn{1}{|c|}{ TC } & 525.000 & 300.000 & 241.667 & 225.000 & 225.000 \\
\hline
\end{tabular}

Sumber : Data Olahan EOQ

Dilihat dari Tabel 5 frekuensi pemesanan mentega selama tahun 2015 dapat dideskipsikan sebagai berikut, untuk pemesanan pertama membutuhkan biaya sebesar Rp 525.000, pada pemesanan kedua membuthkan biaya sebesar Rp 300.000, pemesanan ketiga membutuhkan biaya sebesar Rp 241.667, pemesanan keempat dan kelima adalah pemesanan dengan biaya pemesanan paling ekonomis, yaitu sebesar Rp 225.000. Dengan kuantitas pemesanan 5 kali pesan bisa menghemat pengeluaran bagi Kampoeng Cookies and Rotte dalam pembelian bahan baku untuk membuat berbagai macam roti untuk di jual ke konsumen. Dengan demikian Kampoeng Cookies and Rotte bisa memperkirakan biaya yang harus dikeluarkan untuk membeli mentega untuk salah satu bahan baku utama membuat roti.

Berikut ini bisa dilihat dari total biaya persediaan tahunan mentega (Total Annual Inventory Cost) sesuai data pesanan yang ada:

Tabel 6. Total Biaya Persediaan Mentega Selama Tahun 2015

\begin{tabular}{|l|l|}
\hline$\sum$ Pesanan & Harga perunit \\
\hline 0-499 Kg & Rp. 22.000,- \\
\hline 500 lebih & Rp. 19.000,- \\
\hline
\end{tabular}

Sumber : Kampoeng Cookies and Rotte Dengan rumus:

$$
\mathrm{TAC}=(\mathrm{Q} / 2) \mathrm{C}+(\mathrm{R} / \mathrm{Q}) \mathrm{S}+\mathrm{R}(\mathrm{P})
$$

Keterangan:

$\mathrm{Q}=$ Kuantitas pemesanan (unit/order)

$\mathrm{R}=$ Jumlah pembelian (permintaan) 
selama satu periode

$\mathrm{C}=$ Biaya simpan tahunan dalam Rupiah (unit)

$\mathrm{P}=$ Harga $/ \mathrm{Kg}$

$\mathrm{S}=$ Biaya setiap kali pesan

Dalam hal ini hanya dicari 2 total biaya tahunan pada tingkat EOQ $400 \mathrm{Kg}$ dan $500 \mathrm{Kg}$

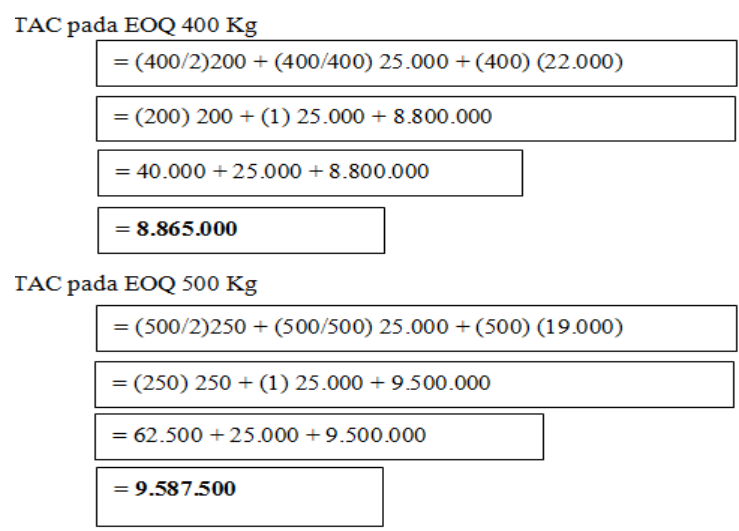

\section{PEMBAHASAN}

Hasil perhitungan EOQ dalam pembelian tepung terigu yang paling ekonomis adalah lebih kurang $300 \mathrm{~kg}$ atau tepatnya 289 kg. Selain itu, Kampoeng Cookies and Rotte juga dapat merencanakan pembelian tepung terigu sebanyak 5 kali pembelian selama 1 tahun, juga dapat menjaga operasianal berjalan dengan lancar tanpa ada kendala karena tidak tersediaanya bahan baku tepung terigu tersebut.

Adanya penghitungan EOQ ini, bertujuan agar Kampoeng Cookies and Rotte dapat mengontrol persediaan yang meminimalkan biaya total dari pemesanan dan penyimpanan, dan setelah menggunakan metode EOQ, Kampoeng Cookies and Rotte dapat mengalihkan biaya yang dikeluarkan untuk pemesanan dan penyimpanan tersebut ke unit lainnya yang lebih membutuhkan banyak biaya. Menggunakan metode EOQ dalam pembelian tepung terigu pada Kampoeng Cookies and Rotte merupakan keputusan yang tepat untuk kemajuan usaha.

Untuk total biaya persediaan tahunan (Total Annual Inventory Cost) bisa dilihat harga bahan baku tepung terigu yang sering dibeli oleh Kampoeng Cookies and Rotte berkisar harga $\mathrm{Rp} 8.000,-$ s/d Rp 9.000,-.
Dalam hal ini Kampoeng Cookies and Rotte harus memilih pembelian dengan harga perkilo dengan harga $\mathrm{Rp} 8.000$,dibadingkan dengan harga $\mathrm{Rp}$ 9.000,dengan total selisih perhitungan sebesar Rp 562.500,- dan tentunya akan lebih menguntungkan, selisih ini juga bisa dimanfaatkan untuk bahan baku yang lainnya.

Dari hasil yang telah diuraikan diatas pembelian ekonomis bahan baku gula adalah lebih kurang $750 \mathrm{Kg}$ pada tingkat harga Rp 14.000,- dan juga bisa Kampoeng Cookies and Rotte bisa merencanakan pembelian dalam 5 kali pembelian selama 1 tahun, dan bisa menjaga operasianal berjalan dengan lancar tanpa ada kendala karena tidak tersediaanya bahan baku gula tersebut, dengan adanya penghitungan EOQ tersebut pemilik usaha dapat membuat atau mengambil keputusan yang tepat untuk operasional dan kemajuan usaha.

Untuk Total Biaya Persediaan Tahunan (Total Annual Inventory Cost) bisa dilihat harga bahan baku gula yang sering dibeli oleh Kampoeng Cookies and Rotte berkisar harga Rp 14.000,- s/d Rp 15.000,tentunya Kampoeng Cookies and Rotte harus memilih pembelian dengan harga perkilo dengan harga $\mathrm{Rp} 14.000$,- dibading dengan harga $\mathrm{Rp} 15.000$,- total selisih sebesar Rp 122.500,- tentunya akan lebih menguntungkan, selisih ini juga bisa dimanfaatkan untuk bahan baku yang lainnya.

Dari hasil perhitungan EOQ dalam pembelian mentega yang paling ekonomis adalah 112 Kg. Selain itu, Kampoeng Cookies and Rotte juga dapat merencanakan pembelian mentega sebanyak 5 kali pembelian selama 1 tahun, juga dapat menjaga operasianal berjalan dengan lancar tanpa ada kendala karena tidak tersediaanya bahan baku tepung terigu tersebut.

Adanya penghitungan EOQ ini, bertujuan agar Kampoeng Cookies and Rotte dapat mengontrol persediaan yang meminimalkan biaya total dari pemesanan dan penyimpanan, dan setelah

p.ISSN: $2407-800 X \quad$ e.ISSN: $2541-4356$ 
menggunakan metode EOQ, Kampoeng Cookies and Rotte dapat mengalihkan biaya yang dikeluarkan untuk pemesanan dan penyimpanan tersebut ke unit lainnya yang lebih membutuhkan banyak biaya. Menggunakan metode EOQ dalam pembelian mentega pada Kampoeng Cookies and Rotte merupakan keputusan yang tepat untuk kemajuan usaha.

Untuk total biaya persediaan tahunan (Total Annual Inventory Cost) bisa dilihat harga bahan baku mentega yang sering dibeli oleh Kampoeng Cookies and Rotte berkisar harga Rp 19.000,- s/d Rp 22.000,-. Dalam hal ini Kampoeng Cookies and Rotte harus memilih pembelian dengan harga perkilo dengan harga $\mathrm{Rp}$ 22.000,- dibadingkan dengan harga $\mathrm{Rp}$ 19.000,- dengan total selisih sebesar Rp 722.500,- dan tentunya akan lebih menguntungkan, selisih ini juga bisa dimanfaatkan untuk bahan baku yang lainnya.

\section{SIMPULAN}

Setelah dilakukan perhitungan persediaan bahan baku terhadap tiga bahan baku utama pada Kampoeng Cookies and Rotte menunjukkan hasil bahwa terdapat efisiensi biaya pada setiap bahan baku, yaitu tepung terigu, gula, dan mentega. Hasil perhitungan setiap bahan baku utama yaitu tepung terigu, gula, dan mentega diketahui bahwa pembelian yang paling optimal dengan biaya paling ekonomis adalah sebanyak 5 kali dalam satu tahun. Dan melihat hasil perhitungan EOQ tersebut, sangat disarankan bagi Kampoeng Cookies and Rotte untuk menggunakan analisis persediaan bahan baku ini untuk usahanya.

\section{DAFTAR RUJUKAN}

Assauri, Sofjan. 2008. Manajemen Produksi dan Operasi. Jakarta: Fakultas Ekonomi Universitas Indonesia.

Fajrin, Eldwidho Hanarista. 2015. Analisis Pengendalian Persediaan Bahan Baku Dengan Menggunakan Metode Economic Order Quantity (EOQ)
Pada Perusahaan Roti Bonansa. Skripsi

Hidayah, Hayati. 2016. Analisis Pengendalian Persediaan Bahan Baku Tepung Terigu Citarasa Bakery pad PT Kaltim Multi Boga Utama (KMBU) di Bontang. eJournal Administrasi Bisnis, 2016, 4 (1):128-141 ISSN 23555408, ejournal.adbisnis.fisipunmul.ac.id

Heizer, Jay dan Barry, Render. 2010. Operations Management: Manajemen Operasi. Buku 2. Edisi Kesembilan. Jakarta: Salemba Empat.

Prihartono, dkk. 2014. Penegndalian Persediaan Bahan Baku dalam Upaya Menjaga Kontinyuitas Produksi pada Perusahaan Tahu UD Sadar Jaya Lumajang. Artikel Ilmiah Hasil Penelitian Mahasiswa 2014

Rianto, Bambang. 2011. Dasar-dasar Pembelanjaan Perusahaan. BPFE Yogyakarta.

Ruauw, Eyverson. 2011. Pengendalian Persediaan Bahan Baku. ASE Volume 7 Nomor 1, Januari 2011: $1-11$

Slamet, Achmad. 2007. Penganggaran Perencanaan dan Pengendalian Usaha.Semarang: UNNES PRESS. 